\title{
Ativação de defesa em cacaueiro contra a murcha-de-verticílio por extratos naturais e acibenzolar-S-metil
}

\author{
Ricardo Borges Pereira(1), Mário Lúcio Vilela de Resende(1), Pedro Martins Ribeiro Júnior ${ }^{(1)}$, \\ Daniel Rufino Amaral ${ }^{(1)}$, Gilvaine Ciavareli Lucas ${ }^{(1)}$ e Fábio Rossi Cavalcanti( ${ }^{(2)}$
}

\begin{abstract}
(1) Universidade Federal de Lavras, Departamento de Fitopatologia, Caixa Postal 3037, CEP $37200-000$ Lavras, MG. E-mail: ricardoborgespereira@yahoo.com.br, mlucio@ufla.br, ribeirojuniorpm@yahoo.com.br, danielrufino78@yahoo.com.br, gilciavareli@yahoo.com.br (2)Universidade Federal do Piauí, Campus Prof. Cinobelina Elvas, CEP 64900-000 Bom Jesus, PI. E-mail: rossi217@yahoo.com.br
\end{abstract}

\begin{abstract}
Resumo - O objetivo deste trabalho foi avaliar o potencial de extratos fúngicos e vegetais na redução da murchade-verticílio do cacaueiro, as atividades da peroxidase e polifenoloxidase e o conteúdo de lignina. Mudas de cacaueiro foram pulverizadas com filtrado de micélio de Rhizopus sp. (FMR), quitosana de Rhizopus sp. (QMR) e Trichoderma sp. (QMT), extratos de casca in natura e seca de maracujá, extrato metanólico de casca seca de frutos de maracujá (MMS) e acibenzolar-S-metil (ASM - $0.2 \mathrm{mg} \mathrm{mL}^{-1}$ ) e sete dias depois, submetidas à inoculação de Verticillium dahliae. O ASM reduziu a murcha-de-verticílio em 38,0\%, seguido dos extratos FMR, QMT, MMS e QMR, que apresentaram reduções em 22,8, 20,1, 19,2 e 15,7\%, respectivamente, em relação à testemunha. Plantas pulverizadas com ASM ou FMR seguidas de inoculação apresentaram aumento da atividade de peroxidase aos oito dias após a pulverização, comparadas às respectivas testemunhas, com pico aos 18 dias após a pulverização. ASM e FMR aumentaram a atividade de polifenoloxidase aos quatro dias após a pulverização. Maiores concentrações de lignina foram obtidas em plantas tratadas com FMR e FMR seguido de inoculação. FMR é um potencial indutor de resistência para manejo de murcha-de-verticílio em cacaueiro.
\end{abstract}

Termos para indexação: Theobroma cacao, Verticillium dahliae, lignina, peroxidase, polifenoloxidase.

\section{Activation of defence responses on cocoa against Verticillium wilt by natural extracts and acibenzolar-S-methyl}

\begin{abstract}
The objective of this work was to assess the potential of fungal and plant extracts on the reduction of Verticillium wilt of cocoa, the activities of the enzymes peroxidase and polyphenoloxidase, as well as the lignin content. Seedlings of cocoa were sprayed with the mycelial filtrate of Rhizopus sp. (FMR), chitosan from Rhizopus sp. (QMR) and Trichoderma sp. (QMT), extracts of fresh and dry passion fruit peel, methanolic extract from dry passion fruit peel (MMS) and acibenzolar-S-methyl (ASM $-0.2 \mathrm{mg} \mathrm{mL}^{-1}$ ) and, inoculed with Verticillium dahliae, seven days later. ASM reduced the cocoa Verticillium wilt in 38.0\%. The extract FMR, QMT, MMS and QMR presented as well reductions of 22.8, 20.1, 19.2 and 15.7\%, respectively, in comparison with the control. Plants sprayed with ASM or FMR followed by inoculation presented increase of peroxidase activity at the $8^{\text {th }}$ day after spraying, compared to the respective controls, with peak at the $18^{\text {th }}$ day after spraying. ASM and FMR increased polyphenoloxidase activity at the $4^{\text {th }}$ day after spraying. Higher lignin concentrations were obtained in plants treated with FMR and FMR following by inoculation. FMR may constitute a potential resistance inducer for the management of the Verticillium wilt of cocoa.
\end{abstract}

Index terms: Theobroma cacao, Verticillium dahliae, lignin, peroxidase, polyphenoloxidase.

\section{Introdução}

Verticillium dahliae Kleb. é um fungo que possui ampla gama de hospedeiros, causando sintomas foliares (epinastia, murcha, amarelecimento e desfolha), vasculares (acúmulo de pigmentos fenólicos oxidados) e declínio (definhamento e morte) (Hiemstra, 1998). Em cacaueiro (Theobroma cacao L.), o patógeno constituise num fator limitante à produção em algumas regiões produtoras da Bahia e Espírito Santo, principalmente em condições de deficiência hídrica, com veranicos prolongados (Luz et al., 1997).

O controle da doença pode ser alcançado por meio da utilização de resistência genética associada a medidas 
culturais, tais como a utilização de mudas sadias, eliminação de restos culturais infectados, adubação equilibrada, irrigação adequada e aplicação de fungicidas sistêmicos, embora o uso destes produtos possa ser inviável, já que o fungo sobrevive em restos vegetais ou no solo, na forma de microescleródios, por períodos prolongados (Goud, 2003). Apesar de a resistência genética ser desejável, material genético com nível satisfatório de resistência ainda não está disponível, embora a cv. Pound 7 tenha se destacado em ensaios de "screening" visando à resistência à doença (Braga \& Silva, 1989).

Ao se considerar a necessidade de desenvolver novas alternativas de controle como parte do manejo integrado, que venham a minimizar o impacto ao ambiente e ao homem, a resistência induzida pode ser usada, uma vez que pode ser obtida pela utilização de produtos naturais, de origem fúngica ou vegetal. A resistência induzida apresenta mecanismos de ação não específicos, de amplo espectro, como resposta ao ataque de diversos patógenos (Oliveira et al., 1997).

Diversos trabalhos enfatizam a existência de substâncias bioativas em extratos vegetais, que proporcionam a ativação do sistema de defesa das plantas contra patógenos, tais como: Phoma sp. (Barguil et al., 2005), Cercospora coffeicola Berk \& Cooke (Santos et al., 2007) e Hemileia vastatrix Berk \& Br em cafeeiro (Santos et al., 2007), além de Xanthomonas campestris pv. vesicatoria (Doidge) Dye em tomateiro (Cavalcanti et al., 2006).

Eliciadores de origem fúngica também têm sido utilizados na ativação de defesas de plantas, como exemplo, a quitosana. Quando aplicada em folhas de várias espécies de plantas, induz resistência local e sistêmica contra infecções causadas por vários vírus, entre eles os vírus-do-mosaico-da-alfafa e do fumo (Pospieszny et al., 1991). A capacidade da quitosana induzir respostas de defesa tem sido demonstrada em várias espécies de plantas, principalmente dicotiledôneas, por meio da formação de caloses e eliciação da produção de peróxido de hidrogênio, aumentando a transcrição/ tradução de genes de defesa da planta que codificam proteínas relacionadas à patogênese e produção de fitoalexinas (Kauss et al., 1997).

Cavalcanti et al. (2006), ao tratar plantas de tomateiro com quitosana obtida de micélio de Crinipellis perniciosa (Stahel) Singer (MCp), quatro dias antes da inoculação de $X$. campestris pv. vesicatoria, obtiveram redução de $42,3 \%$ da mancha-bacteriana em casa de vegetação. A resistência induzida em plantas tratadas com MCp, segundo os autores, pode ser evidenciada pelos altos picos de atividades das enzimas relacionadas com a defesa, tais como peroxidase, polifenoloxidase, quitinase, além de proporcionar maiores concentrações de lignina e de outros compostos fenólicos.

O objetivo deste trabalho foi avaliar a ação de extratos fúngicos e vegetais na redução da murcha-de-verticílio em mudas de cacaueiro e na atividade das enzimas de defesa, peroxidase e polifenoloxidase, assim como na lignificação.

\section{Material e Métodos}

Os experimentos foram realizados no primeiro semestre de 2005, na Universidade Federal de Lavras, Lavras, MG. Para a realização dos experimentos, foram obtidos, inicialmente, três extratos de origem fúngica e três de origem vegetal, produzidos conforme a metodologia descrita a seguir.

Filtrado de micélio de Rhizopus sp. (FMR): três discos de micélio de $6 \mathrm{~mm}$ de diâmetro foram retirados das margens de uma colônia de Rhizopus sp. e transferidos para erlenmeyers esterilizados de $250 \mathrm{~mL}$, contendo $150 \mathrm{~mL}$ de meio BD (200 g de batata e $20 \mathrm{~g}$ de dextrose por litro de água destilada). Os erlenmeyers foram dispostos em agitador orbital, a $100 \mathrm{rpm}$ em condições de temperatura ambiente. Depois de quatro dias, a biomassa obtida foi filtrada a vácuo em funil de Buchner acoplado a um Kitazato utilizando papel Whatman, o que permitiu a separação da biomassa do meio líquido. A biomassa foi lavada, ressuspensa em $200 \mathrm{~mL}$ de água destilada, transferida para um balão volumétrico de 1,0 L de capacidade, e submetida a um tratamento térmico a $100^{\circ} \mathrm{C}$ durante uma hora em refluxo. Após o resfriamento, o micélio foi novamente filtrado sob condições assépticas e a fase líquida coletada e acondicionada em freezer a $-20^{\circ} \mathrm{C}$ para uso posterior.

Quitosana de micélio de Rhizopus sp. (QMR): frações heterogêneas de quitosana provenientes de micélio de Rhizopus sp., obtidas durante a segunda filtração de micélio de Rhizopus sp., foram separadas e secadas ao ar, sob condições refrigeradas e assépticas. Em seguida, foram submetidas ao procedimento para extração de quitosana descrito por Synowiecki \& Al-Khateeb (1997), em que $20 \mathrm{~g}$ de massa fúngica foram misturados a uma solução de hidróxido de sódio na proporção 1:30 (p/v) e tratados termicamente, por 2 horas, a $90^{\circ} \mathrm{C}$, para 
desproteinização. O material foi centrifugado a $4.000 \mathrm{~g}$ por 15 min e o sobrenadante descartado. O precipitado foi lavado até o equilíbrio do $\mathrm{pH}$ em 7,0 e, em seguida, pesado e misturado em uma solução de ácido acético $10 \%$ na proporção de 1:40 (p/v). O sistema foi mantido a $60^{\circ} \mathrm{C}$ por 6 horas para o amolecimento e extração de quitosana. $\mathrm{O}$ material foi novamente filtrado e lavado até o equilíbrio em $\mathrm{pH} 7,0$. A biomassa foi transferida para um misturador, adicionando-se água destilada na proporção de 1:5 (p/v), onde permaneceu, sob condição de desintegração, até a obtenção de uma suspensão finamente dividida. A amostra foi então acondicionada em freezer a $-20^{\circ} \mathrm{C}$ para uso posterior.

Quitosana de micélio de Trichoderma sp. (QMT): a fração quitosana de Trichoderma sp. foi calculada conforme a metodologia utilizada para obtenção do QMR.

Extrato aquoso de casca de maracujá in natura (CMN): frutos de maracujá (Passiflora edulis Sims) foram previamente selecionados, lavados e despolpados. Em seguida, $500 \mathrm{~g}$ de casca fresca foram picados em cubos de $0,5 \mathrm{~cm}^{3}$ e ressuspensos em $0,5 \mathrm{~L}$ de água destilada. O conjunto foi submetido ao tratamento térmico a $100^{\circ} \mathrm{C}$ por 2 horas sob refluxo e, após o resfriamento, o extrato foi filtrado em gaze e o resíduo descartado. $\mathrm{O}$ filtrado foi armazenado em freezer a $-20^{\circ} \mathrm{C}$ para uso posterior.

Extrato aquoso de casca de maracujá seca (CMS): cascas de frutos de maracujá obtidas anteriormente foram secadas em estufa a $60^{\circ} \mathrm{C}$ por 48 horas e moídas até a obtenção de uma fração bem fina (pó). Foram adicionados 7,67 $\mathrm{g}$ da fração e $100 \mathrm{~mL}$ de água destilada em cada erlenmeyer de $250 \mathrm{~mL}$. Os erlenmeyers foram dispostos em um agitador orbital, onde permaneceram, sob agitação a $130 \mathrm{rpm}$, à temperatura ambiente por 3 horas. Após este período, foi realizada a filtragem a vácuo e o extrato foi armazenado em freezer a $-20^{\circ} \mathrm{C}$ para uso posterior.

Extrato metanólico de casca de maracujá seca (MMS): $200 \mathrm{~g}$ da fração obtida anteriormente foram ressuspensos em metanol (quantidade suficiente para cobrir a fração), tendo permanecido em repouso por 24 horas. Em seguida, foi realizada a filtração para a coleta do extrato e o resíduo foi submetido a uma nova extração por mais 24 horas. Os extratos coletados foram transferidos para balões volumétricos de $250 \mathrm{~mL}$ e submetidos à evaporação do solvente em rotoevaporador a $50 \mathrm{rpm}$ e temperatura de $30^{\circ} \mathrm{C}$. $\mathrm{O}$ precipitado foi ressuspenso em $30 \mathrm{~mL}$ de água destilada, homogeneizado e armazenado em freezer a $-20^{\circ} \mathrm{C}$ para uso posterior. O extrato foi diluído em água na proporção de 1:40 antes de ser utilizado.

Na produção de mudas de cacau a serem utilizadas, sementes da cultivar EEG 64, suscetíveis a V. dahliae, foram pré-germinadas em vermiculita e transplantadas para sacos de polietileno de $3 \mathrm{~L}$ com substrato composto de solo, areia e esterco bovino (2:1:1). Na produção de mudas a serem utilizadas nos ensaios bioquímicos, sementes pré-germinadas da mesma cultivar foram transplantadas para bandejas de isopor com o substrato Plantmax HT (0,4 L por célula), ao qual foi adicionada solução nutritiva de Hoagland \& Arnon (1950) até a formação do segundo par de folhas verdadeiras. As mudas de cacau foram mantidas em casa de vegetação durante todo o período experimental, em temperatura de $25 \pm 3^{\circ} \mathrm{C}$ e umidade relativa do ar em torno de $80 \%$. As mudas foram controladas por um sistema automatizado de nebulização e irrigadas diariamente.

$\mathrm{Na}$ inoculação do fungo, foi utilizado um isolado cultivado em meio BDA durante 25 dias, a $25 \pm 1^{\circ} \mathrm{C}$, sob fotoperíodo de 12 horas. O inóculo foi obtido pela adição de $20 \mathrm{~mL}$ de água destilada por placa, seguido da raspagem da colônia. A suspensão obtida foi filtrada em gaze e sua concentração ajustada, em hemocitômetro, para $1,0 \times 10^{5}$ esporos viáveis por mililitro.

$\mathrm{Na}$ avaliação do efeito dos extratos sobre a severidade da murcha-de-verticílio, mudas com 50 dias de idade foram pulverizadas com os extratos fúngicos e vegetais, até o ponto de escorrimento. Como testemunhas, foram mantidas plantas somente com inóculos, além de um tratamentopadrão de indução de resistência em cacau, utilizando-se o acibenzolar-S-metil (ASM-0,2 $\mathrm{mg} \mathrm{mL}^{-1}$ ). Sete dias após a aplicação, as plantas receberam inóculos de $V$. dahliae por meio de punção no caule, utilizando-se seringas e agulhas estéreis, conforme método descrito por Bugbee \& Presley (1967). Uma gota de $10 \mu \mathrm{L}$ da suspensão de esporos foi utilizada na inoculação em cada planta e a água, inserida logo acima do nó cotiledonar até atingir o lenho. As testemunhas absolutas foram injetadas apenas com água destilada. $\mathrm{O}$ delineamento experimental foi de blocos casualizados, com três repetições e as parcelas, compostas por 14 plantas. Avaliações dos experimentos foram realizadas aos 20, 30, 40, 50 e 60 dias após a inoculação, utilizando-se uma escala de notas variando de 0 (zero) a 4, descrita por Sidhu \& Webster (1977), em que 0 corresponde à ausência de sintomas e 4 corresponde a plantas mortas. As notas foram transformadas em 
níveis de severidade utilizando-se o índice de Mckinney (1923), tendo sido calculada a área abaixo da curva de progresso da severidade da doença (AACPSD), de acordo com Shaner \& Finney (1977). Os níveis de controle foram estimados pela relação $1-\mathrm{x} / \mathrm{y}$, em que $\mathrm{x}$ representa a AACPSD das plantas tratadas, e y representa a AACPSD dos controles com inoculação (Li et al., 1996).

$\mathrm{Na}$ determinação das enzimas peroxidase e polifenoloxidase, e do acúmulo de lignina nos tecidos, foram selecionados dois tratamentos com maior eficácia no controle da doença em casa de vegetação, no caso, filtrado do micélio de Rhizopus sp. (FMR) e o tratamento-padrão, utilizando-se acibenzolar-S-metil (ASM). O experimento constituiu-se dos seguintes tratamentos: FMR; FMR seguido de inoculação; ASM $0,2 \mathrm{mg} \mathrm{mL}^{-1}$; ASM $0,2 \mathrm{mg} \mathrm{mL}^{-1}$ seguido de inoculação; testemunha, somente com inoculação. Plântulas com 30 dias de idade foram pulverizadas até o ponto de escorrimento e, após quatro dias, submetidas à inoculação conforme método descrito por Bugbee \& Presley (1967). O delineamento utilizado foi o de blocos casualizados, com três repetições e parcelas compostas de duas plantas.

Amostras utilizadas na quantificação de proteínas totais e atividade das enzimas peroxidase e polifenoloxidase foram coletadas aos 4, 8, 13 e 18 dias após a aplicação dos tratamentos, coletando-se o epicótilo das mudas. Por ocasião da última amostragem, foram então coletadas folhas para a quantificação de ligninas totais. Imediatamente após cada coleta, as folhas foram congeladas em nitrogênio líquido e armazenadas a $-80^{\circ} \mathrm{C}$ até o momento da maceração. Na quantificação de proteínas totais e atividade de peroxidases e polifenoloxidases, $1,5 \mathrm{~g}$ do epicótilo das plântulas de cada tratamento foi macerado em almofariz com tampão acetato de sódio $50 \mathrm{mM}, \mathrm{pH}$ 5,2, com cloreto de sódio $0,5 \mathrm{M}$ e ácido cítrico $0,4 \%$, durante $5 \mathrm{~min}$ em banho de gelo. Em seguida, a mistura foi filtrada em pano de trama fina e a suspensão foi centrifugada a $4.000 \mathrm{~g}$ por $15 \mathrm{~min}$, a $4^{\circ} \mathrm{C}$. O sobrenadante coletado para ser usado como fonte enzimática foi mantido a $-80^{\circ} \mathrm{C}$ até o momento das análises.

As proteínas solúveis contidas nos extratos foram aferidas pelo ensaio de Bradford (1976), utilizando-se um padrão de albumina sérica bovina (BSA). As atividades de peroxidase e polifenoloxidase foram determinadas de acordo com o método de Kar \& Mishra (1976), utilizando-se, respectivamente, guaiacol na presença de peróxido de hidrogênio, e pirocatecol na ausência de peróxido de hidrogênio, tendo os resultados expressos em unidade de atividade enzimática por miligrama de proteína por minuto. A quantificação de lignina foi determinada por meio do ensaio com ácido tioglicólico (Monties, 1989), com base em uma curvapadrão construída com diferentes concentrações de lignina-padrão (alkali, 2-hidroxipropil éter). Os resultados foram expressos em miligramas de lignina por grama de matéria fresca.

Paralelamente, foi realizado um ensaio in vitro, com o objetivo de examinar o potencial da inibição dos extratos e do ASM sobre a germinação de esporos de V. dahliae. Os extratos foram testados nas mesmas concentrações usadas nos testes in vivo, utilizando-se água destilada esterilizada como testemunha. O ensaio foi conduzido obedecendo a um delineamento inteiramente casualizado, com seis repetições, utilizando-se lâminas escavadas com três cavidades, onde foram depositados, além de $40 \mu \mathrm{L}$ de uma suspensão de conídios $\left(1,0 \times 10^{5}\right.$ conídios $\left.\mathrm{mL}^{-1}\right)$, $40 \mu \mathrm{L}$ de cada extrato. As lâminas foram incubadas em ambiente saturado de água a $25^{\circ} \mathrm{C}$, em fotoperíodo de 12 horas, e as avaliações efetuadas 24 horas após, utilizando-se um microscópio de luz.

Estatística descritiva, análise de variância e teste de Scott-Knot, a 5\% de probabilidade, foram realizados como auxílio do SISVAR (Ferreira, 2000).

\section{Resultados e Discussão}

No experimento realizado em casa de vegetação, todos os tratamentos reduziram a severidade da murcha-deverticílio em relação à testemunha, exceto o extrato aquoso de casca de maracujá seca (CMS) e o extrato aquoso de casca de maracujá in natura (CMN) (Figura 1). De maneira geral, plantas pulverizadas com as substâncias testadas atingiram valores máximos de incidência e severidade da doença aos 40 e 60 dias após inoculação de $V$. dahliae. Os melhores resultados quanto à redução da severidade foram obtidos em plantas pulverizadas com ASM, previamente à inoculação de V. dahliae, o que proporcionou uma proteção de $38,0 \%$ ao final das avaliações.

O filtrado de micélio de Rhizopus sp. (FMR) apresentou redução da severidade da doença em 22,8\% ao final das avaliações, entretanto, sem diferir estatisticamente do extrato de quitosana de micélio de Trichoderma sp. (QMT), extrato metanólico de casca de maracujá seca (MMS) e do extrato de quitosana de 
micélio de Rhizopus sp. (QMR), que apresentaram reduções da severidade em 20,1, 19,2 e 15,7\% em relação à testemunha. Resultados semelhantes foram obtidos por Resende et al. (2002), em plantas de cacau tratadas com ASM aos 15 e 7 dias antes da inoculação de $V$. dahliae, as quais apresentaram redução da murcha em 55 e $18 \%$, respectivamente.

Segundo Kúc (2001), indutores de resistência sensu stricto não atuam diretamente sobre o patógeno. Contudo, nos indutores lato sensu podem atuar tanto induzindo resistência como afetando diretamente o patógeno (Hofgaard et al., 2005). O filtrado de micélio de Rhizopus sp. e o extrato aquoso de casca de maracujá seca apresentaram 100 e 97,2\% de inibição da germinação, ao passo que o extrato aquoso de casca de maracujá in natura apresentou inibição de 86,8\%.

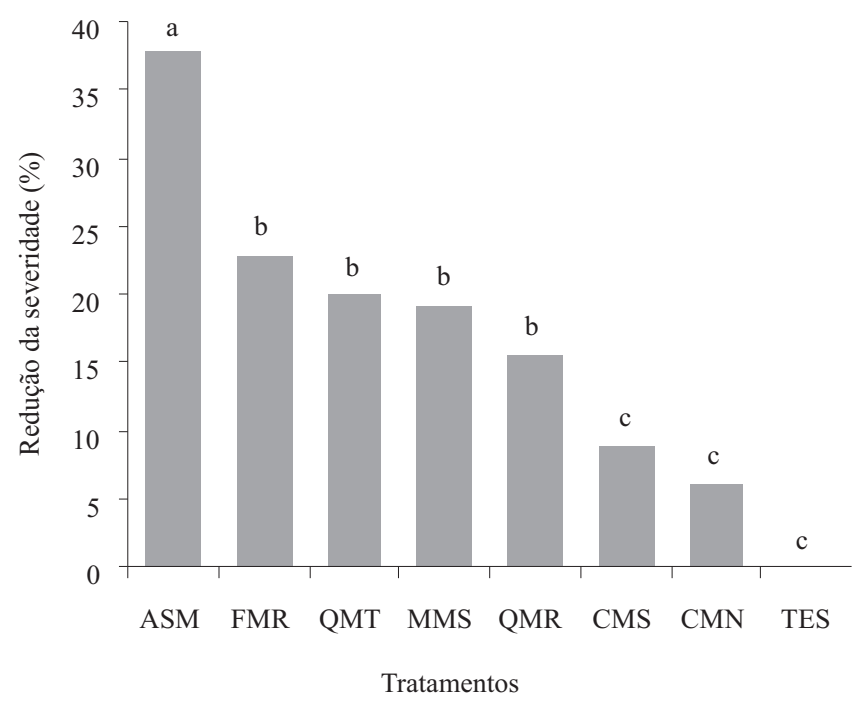

Figura 1. Redução da severidade da murcha-de-verticílio aos 60 dias após inoculação de Verticillium dahliae em mudas de cacaueiro, cultivar EEG 64, tratadas com: ASM, acibenzolarS-metil (0,2 $\left.\mathrm{g} \mathrm{L}^{-1}\right)$; FMR, filtrado de micélio de Rhizopus sp.; QMT, quitosana de micélio de Trichoderma sp.; MMS, extrato metanólico de casca de maracujá seca; QMR, quitosana de micélio de Rhizopus sp.; CMS, extrato aquoso de casca de maracujá seca; CMN, extrato aquoso de casca de maracujá in natura; e TES, testemunha. As substâncias testadas foram pulverizadas nas folhas 50 dias após o plantio, e as plantas submetidas à inoculação sete dias após a pulverização. As reduções da severidade foram obtidas a partir das AACPSD, após cinco avaliações (testemunha $=0 \%$ de proteção). Colunas com letras iguais não diferem entre si, de acordo com o teste de Scott-Knott, a 5\% de probabilidade.
Os tratamentos constituídos de frações de quitosana de Trichoderma sp. e Rhizopus sp. não diferiram entre si, tendo apresentado inibições de 70,1 e 70\%, respectivamente, em relação à testemunha. Os tratamentos que apresentaram as menores inibições foram: o extrato metanólico de casca de maracujá seca e ASM, com 58,2 e 50,6\% de inibição. Conforme dados obtidos no ensaio realizado in vitro, todos os tratamentos apresentaram inibição da germinação de esporos de V. dahliae.

Agentes bióticos, quer sejam microrganismos viáveis ou inativados, podem ativar mecanismos de defesa da planta (Stangarlin \& Pascholati, 1994). Pacumbaba et al. (1999) demonstraram que lixiviados obtidos a partir de cultivo de Lentinula edodes (cogumelo shiitake), em meio líquido, reduziram as murchas-bacterianas do tomateiro e do feijoeiro causadas, respectivamente, por Ralstonia solanacearum (Smith) Smith e Clavibacter flaccumfaciens pv. flaccumfaciens. O lixiviado também apresentou atividade inibitória in vitro sobre bactérias fitopatogênicas, o que leva a crer que o controle pode ter ocorrido por antibiose. Algumas dessas moléculas naturais utilizadas como indutores de resistência em plantas são geralmente oligossacarídeos da parede celular de patógenos, como glucanas, derivados de quitina, glicoproteínas, peptídeos e polissacarídeos da parede celular (Hann, 1996).

Paralelamente à redução da severidade da murchade-verticílio, promovida por ASM e pelo filtrado de micélio de Rhizopus sp., houve aumento relativo das atividades das enzimas peroxidase e polifenoloxidase (Figura 2). Plantas pulverizadas com ASM, adotado como padrão de indução de resistência, apresentaram picos de atividade de peroxidase aos oito dias após a pulverização (DAP), com redução de atividade aos 13 e 18 DAP, porém ainda com atividade superior aos controles aos 13 DAP (Figura 2 A). Plantas testemunhas, somente com inoculação do patógeno, apresentaram pico de atividade de peroxidase somente aos 18 DAP. Esse comportamento demonstra que a inoculação por meio de punção no caule, por si só, também promoveu aumento na atividade de peroxidase, o que pode ser uma resposta da planta ao ferimento. Plantas pulverizadas com filtrado de micélio de Rhizopus sp., e com inoculação do patógeno, apresentaram pico de atividade dessa enzima aos 8 DAP, tendo diferido do tratamento-controle seguido de inoculação e, voltado a atingir um novo pico, juntamente com o controle com inoculação aos 18 DAP (Figura 2 B). 
A atividade de peroxidase tem sido associada a uma variedade de processos relacionados à defesa em plantas, até mesmo reações de hipersensibilidade, lignificação e suberização (Silva et al., 2007). Di Piero \& Pascholati (2004) observaram picos de atividade de peroxidase aos 9 e 12 DAP, respectivamente, em plantas de pepino tratadas com extratos aquosos de L. edodes e desafiadas por Colletotrichum lagenarium (Pass.) Ellis \& Halst.

Em relação à enzima polifenoloxidase em plantas tratadas com ASM, e com filtrado de micélio de Rhizopus sp., foram observados picos de atividade logo aos 4 DAP, o que diferiu das plantas testemunhas sem inoculação, que apresentaram atividades mais baixas
(Figura $2 \mathrm{C}$ e D). Todos os tratamentos avaliados apresentaram atividades reduzidas aos 8 DAP, mantendo-se estáveis até aos $18 \mathrm{DAP}$, não tendo apresentado, entretanto, diferenças das testemunhas.

Silva (2007), ao testar extratos aquosos de Agaricus blazei e ASM $\left(0,05 \mathrm{mg} \mathrm{mL}^{-1}\right)$ em plantas de berinjela contra $R$. solanacearum, obteve aumento na atividade de peroxidase para ambos, aos 7 e 12 DAP, respectivamente. Entretanto, não encontrou qualquer atividade da enzima polifenoloxidase em plantas tratadas com ASM, embora em plantas tratadas com extrato aquoso de A. blazei tenha sido detectada aos 7 DAP. Silva et al. (2007), por sua vez, observaram aumento significativo na atividade de peroxidase em plantas de
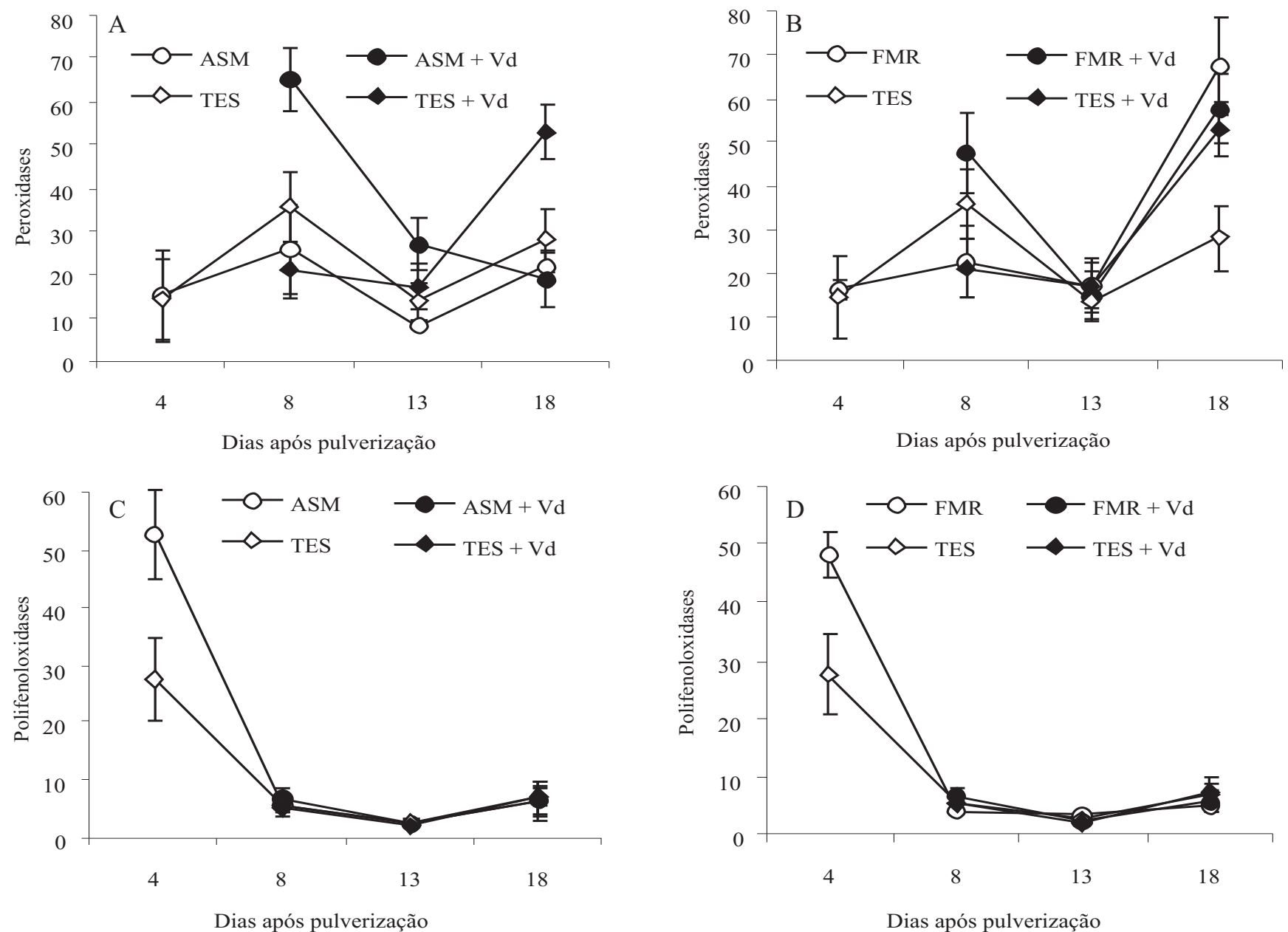

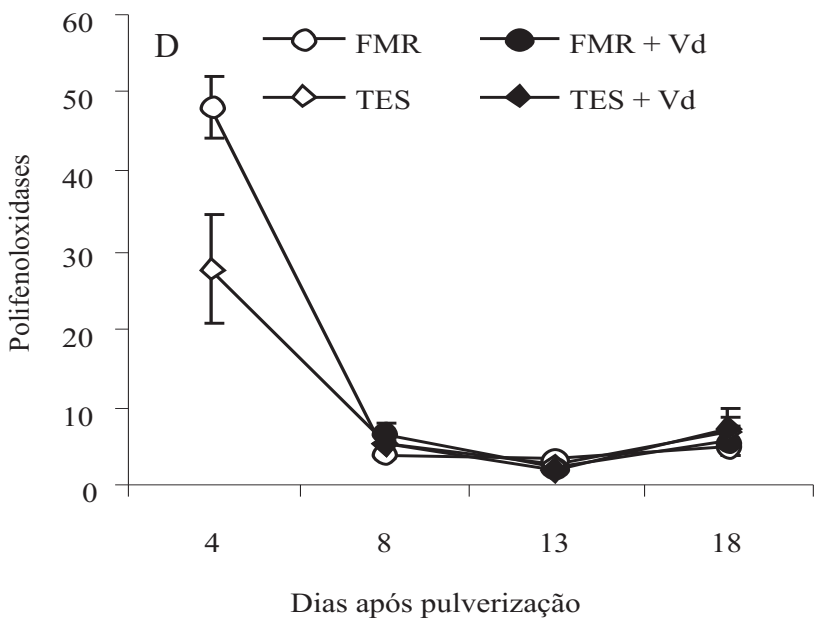

Figura 2. Atividade de peroxidases e polifenoloxidases (UA por mg de proteína por min) em epicótilos de plântulas de cacaueiro, cultivar EEG 64, aos 4, 8, 13 e 18 dias após pulverização. A e C: plantas com 30 dias foram pulverizadas com ASM (acibenzolarS-metil - 0,2 $\mathrm{g} \mathrm{L}^{-1}$ ); B e D: plantas com 30 dias foram pulverizadas com FMR (filtrado de micélio de Rhizopus sp.) e, após quatro dias submetidas à inoculação de Verticillium dahliae (+ Vd). TES: testemunha. Barras de erros indicam desvio-padrão da média. 
tomateiro tratadas com $\operatorname{ASM}\left(0,05 \mathrm{mg} \mathrm{mL}^{-1}\right)$, porém sem inoculação de $R$. solanacearum. Extratos aquosos de L. edodes e A. blazei também apresentaram aumento de atividade de peroxidase aos 3, 7 e 12 DAP. Em relação à polifenoloxidase, plantas tratadas somente com esses extratos apresentaram atividades superiores às respectivas testemunhas, aos 3, 7 e 12 DAP.

Em relação às concentrações de lignina ácido-solúvel total, plantas tratadas com filtrado de micélio de Rhizopus sp. e as tratadas e com inoculação de $V$. dahliae apresentaram maiores concentrações em relação aos demais tratamentos, seguido de plantas tratadas com ASM, tratamento com ASM seguido de inoculação e testemunha com inoculação (Figura 3). Todos os tratamentos apresentaram concentrações de lignina superiores à testemunha. Tratamentos seguidos de inoculação apresentaram pequenos incrementos de lignina em relação aos sem inoculação. Tal fenômeno pode ter ocorrido em virtude do reconhecimento do patógeno pelo hospedeiro. Segundo Kúc (2001), a

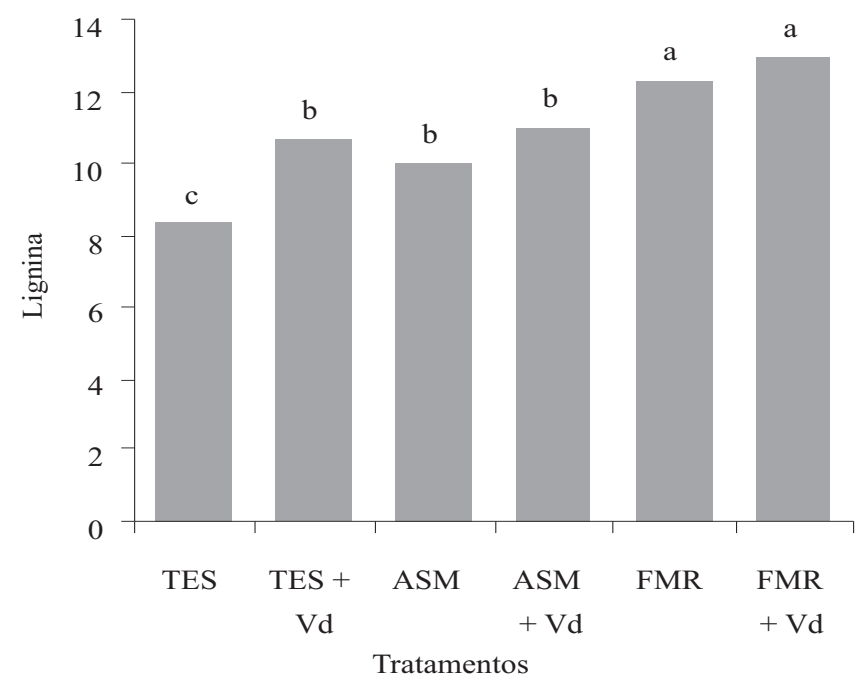

Figura 3. Concentração de lignina ácido-solúvel total (miligramas por grama de matéria fresca) em epicótilos de plântulas de cacaueiro, cultivar EEG 64, aos 18 dias após pulverização com: ASM, acibenzolar-S-metil (0,2 g L-1); e FMR, filtrado de micélio de Rhizopus sp. Após quatro dias das pulverizações, as plantas foram submetidas à inoculação de Verticillium dahliae (+ Vd). TES: testemunha. Colunas com letras iguais não diferem entre si, de acordo com o teste de Scott-Knott, a $5 \%$ de probabilidade. lignificação da parede celular é caracterizada como uma das reações desencadeadas pelo sistema de defesa da planta no sentido de impedir a penetração ou restringir a colonização dos tecidos por patógenos.

Diante dos resultados obtidos, pode-se sugerir que o controle da murcha-de-verticílio com filtrado de micélio de Rhizopus sp. deve-se ao efeito tóxico direto deste e também ao efeito de indução de resistência em plantas de cacaueiro. Apesar de o extrato ter apresentado efeito direto sobre o patógeno, ele também propiciou aumento na atividade de peroxidase, polifenoloxidase e acúmulo de lignina.

\section{Conclusões}

1. Acibenzolar-S-metil, filtrado de micélio de Rhizopus sp., extrato de quitosana de micélio de Trichoderma sp., extrato metanólico de casca de maracujá seca e extrato de quitosana de micélio de Rhizopus sp. conferem capacidade parcial de proteção em plantas de cacaueiro desafiadas por Verticillium dahliae.

2. Acibenzolar-S-metil e filtrado de micélio de Rhizopus sp. são capazes de promover aumento na atividade de enzimas (peroxidase e polifenoloxidase) relacionadas à patogênese e ao acúmulo de lignina em epicótilo de plântulas de cacaueiro.

\section{Agradecimentos}

Ao Conselho Nacional de Desenvolvimento Científico e Tecnológico, pelo apoio financeiro.

\section{Referências}

BARGUIL, B.M.; RESENDE, M.L.V.; RESENDE, R.S.; BESERRA JÚNIOR, J.E.A.; SALGADO, S.M.L. Effect of extracts from citric biomass, rusted coffee leaves and coffee berry husks on Phoma costaricencis of coffee plants. Fitopatologia Brasileira, v.30, p.535-537, 2005.

BRADFORD, M.M. A rapid and sensitive method for the quantitation of microgram quantities of protein utilizing principle of protein-dye binding. Analitical Biochemistry, v.72, p.248-254, 1976.

BRAGA, M.C.T.; SILVA, S.D.V.M. Resistência do cacaueiro (Theobroma cacao L.) a Verticillium dahliae Kleb. Agrotrópica, v.1, p.116-121, 1989.

BUGBEE, W.M.; PRESLEY, T.J. A rapid inoculation technique to evaluate the resistance of cotton to Verticillium albo-atrum. Phytopathology, v.57, p.1264, 1967. 
CAVALCANTI, F.R.; RESENDE, M.L.V.; PEREIRA, R.B.; COSTA, J.C.B.; CARVALHO, C.P.S. Atividades de quitinase e beta-1, 3-glucanase após eliciação das defesas do tomateiro contra a manchabacteriana. Pesquisa Agropecuária Brasileira, v.41, p.1721-1730, 2006.

DI PIERO, R.M.; PASCHOLATI, S.F. Indução de resistência em plantas de pepino contra Colletotrichum lagenarium pela aplicação de extratos de basidiocarpos de Lentinula edodes e de Agaricus blazei. Summa Phytopathologica, v.30, p.243-250, 2004.

FERREIRA, D.F. Análises estatísticas por meio do Sisvar para Windows versão 4.0. In: REUNIÃO ANUAL DA REGIÃO BRASILEIRA DA SOCIEDADE INTERNACIONAL DE BIOMETRIA, 45., 2000, São Carlos. Anais. São Carlos: Universidade Federal de São Carlos, 2000. p.255-258.

GOUD, J.C. Verticillium wilt in trees: detection, prediction and disease management. 2003. 98p. Thesis (Ph.D.) - Wageningen Universiteit, Wageningen.

HANN, M.G. Microbial elicitors and their receptors in plants. Annual Review of Phytopathology, v.34, p.387-412, 1996.

HIEMSTRA, J.A. Some general features of verticillium wilts in trees. In: HIEMSTRA, J.A.; HARRIS, D.C. (Ed.). A compendium of verticillium wilts in tree species. Wageningen: CPRO-DLO/ HRI-EM, 1998. p.5-11.

HOAGLAND, D.R.; ARNON, D.I. The water culture method for growing plants without soil. California: University of California Agricultural Experimental Station, 1950.34p.

HOFGAARD, I.S.; ERGON, A.; WANNER, L.A.; TRONSMO, A.M. The effect of chitosan and Bion on resistence to pink snow mould in perennial ryegrass and winter wheat. Journal of Phytopathololy, v.153, p.108-119, 2005.

KAR, M.E.; MISHRA, D. Catalase, peroxidase and polyphenoloxidase activities during rice leaf senescence. Plant Physiology, v.57, p.315-319, 1976.

KAUSS, H.; JEBLICK, W.; DOMARD, A.; SIEGRIST, A.J. Partial acetylation of chitosan and a conditioning period are essential for elicitation of $\mathrm{H}_{2} \mathrm{O}_{2}$ in surface-abraded tissues from various plants. In: DOMARD, A.; ROBERTS, G.A.F. (Ed.). Advances in Chitin Science. Lyon: Jacques André, 1997. p.94-101.

KÚC, J. Concepts and direction of induced systemic resistance in plants and its application. European Journal of Plant Pathology, v.107, p.7-12, 2001.

LI, J.; ZINGEN-SELL, I.; BUCHENAUER, H. Induction of resistance of cotton plants to Verticillium wilt and of tomato plants to Fusarium wilt by $\beta$-aminobutyric acid and methyl jasmonate. Journal of Plant Diseases and Plant Protection, v.103, p.288299, 1996.

LUZ, E.D.M.N.; BEZERRA, J.L.; RESENDE, M.L.V.; OLIVEIRA, M.L. de. Cacau (Theobroma cacao L.) - controle de doenças. In: VALLE, F.X.R.; ZAMBOLIM, L. (Ed.). Controle de doenças de plantas. Viçosa: UFV, 1997. p.611-665.
MCKINNEY, H.H. Influence of soil temperature and moisture on infection of wheat seedlings by Helmintosporium sativum. Journal of Agricultural Research, v.26, p.195-219, 1923.

MONTIES, B. Lignins. In: DEY, P.M.; HARBORNE, J.B. (Ed.). Methods in plant biochemistry. New York: Academic Press, 1989. p.113-158.

OLIVEIRA, R.F.; PASCHOLATI, S.F.; LEITE, B. Papilla formation and peroxidase activity in Mimosa scabrella hypocotyls inoculated with the non-pathogen Colletotrichum graminicola. Fitopatologia Brasileira, v.22, p.195-197, 1997.

PACUMBABA, R.P.; BEYL, C.A.; PACUMBABA JÚNIOR, R.O. Shiitake mycelial leachate supresses growth of some bacterial species and symptoms of bacterial wilt of tomato and lima bean in vitro. Plant Disease, v.83, p.20-23, 1999.

POSPIESZNY, H.; CHIRKOV, S.; ATABEKOV, J. Induction of antiviral resistance in plants by chitosan. Plant Science, v.79, p.6368, 1991.

RESENDE, M.L.V.; NOJOSA, G.B.A.; CAVALCANTI, L.S.; AGUILAR, M.A.G.; SILVA, L.H.C.P.; PEREZ, J.O.; ANDRADE, G.C.G.; CARVALHO, G.A.; CASTRO, R.M. Induction of resistance in cocoa against Crinipellis perniciosa and Verticillium dahliae by acibenzolar-S-methyl (ASM). Plant Pathology, v.51, p.621-628, 2002.

SANTOS, F.S.; SOUZA, P.E.; RESENDE, M.L.V.; POZZA, E.A.; MIRANDA, J.C.; RIBEIRO JÚNIOR, P.M.; MANERBA, F.C. Efeito de extratos vegetais no progresso de doenças foliares do cafeeiro orgânico. Fitopatologia Brasileira, v.32, p.59-63, 2007.

SHANER, G.; FINNEY, R.F. The effect of nitrogen fertilization on the expression of slow-mildewing resistance in knox wheat. Phytopathology, v.67, p.1051-1056, 1977.

SIDHU, G.S.; WEBSTER, J.M. The use of aminoacid fungal auxotrophs to study the predisposition phenomena in the root-knot: wilt fungus disease complex. Physiological Plant Pathology, v.11, p.117-127, 1977.

SILVA, R.F. Indução de resistência em plantas de berinjela e tomate por Lentinula edodes e Agaricus blazei contra bactérias causadoras de murchas (Rasltonia solanacearum) e cancro (Clavibacter michiganensis subsp. michiganensis). 2007. 109p. Tese (Doutorado) - Escola Superior de Agricultura Luiz de Queiroz, Piracicaba.

SILVA, R.F.; PASCHOLATI, S.F.; BEDENDO, I.P. Indução de resistência em tomateiro por extratos aquosos de Lentinula edodes e Agaricus blazei contra Ralstonia solanacearum. Fitopatologia Brasileira, v.32, p.189-196, 2007.

STANGARLIN, J.R.; PASCHOLATI, S.F. Proteção de plântulas de milho pipoca contra Exserohilum turcicum pelo uso de Saccharomyces cerevisiae. Summa Phytopathologica, v.20, p.1621, 1994.

SYNOWIECKI, J.; AL-KHATEEB, N.A.Q. Mycelia of Mucor rouxii as a source of chitin and chitosan. Food Chemistry, v.60, p.605610, 1997.

Recebido em 20 de setembro de 2007 e aprovado em 13 de fevereiro de 2008 